\title{
Suplementos alimentares: uma fonte de doping não intencional?
}

\section{Food supplements: an unintended doping source?}

\author{
Bruno Ruiz Brandão da Costa ${ }^{1}$, Márcia Nogueira da Silva de la Cruz ${ }^{2 *}$ (D), \\ Rafaela Rocha Roiffé ${ }^{1,3}$ (D), Monica Costa Padilha ${ }^{1,2}$
}

${ }^{1}$ Universidade Federal do Rio de Janeiro (UFRJ), Instituto de Química, Laboratório de Apoio ao Desenvolvimento Tecnológico (LADETEC), Rio de Janeiro/RJ - Brasil

${ }^{2}$ Universidade Federal do Rio de Janeiro (UFRJ), Instituto de Química, Departamento de Química Analítica (DQA),

Rio de Janeiro/RJ - Brasil

${ }^{3}$ Instituto Militar de Engenharia (IME), Departamento de Engenharia Química, Rio de Janeiro/RJ - Brasil

*Corresponding author: Márcia Nogueira da Silva de la Cruz, Universidade Federal do Rio de Janeiro (UFRJ), Instituto de Química, Departamento de Química Analítica (DQA), Avenida Athos da Silveira Ramos, 149 Bloco A $5^{\circ}$ andar sala 507, Cidade Universitária, CEP: 21941-598, Rio de Janeiro/RJ - Brasil, E-mail: marcianogueira@iq.ufrj.br

Cite as: Costa, B. R. B., de la Cruz, M. N. S., Roiffé, R. R., \& Padilha, M. C. (2021). Food supplements: an unintended doping source? Brazilian Journal of Food Technology, 24, e2019256. https://doi.org/10.1590/19816723.25619

\section{Resumo}

O excessivo consumo de suplementos alimentares, aliado a uma legislação inespecífica e a um controle de qualidade ineficiente, faz com que a saúde dos consumidores seja colocada em risco devido à possível existência de contaminantes, em especial pró-hormônios, esteroides anabolizantes e estimulantes. Estes compostos podem proporcionar um aumento do desempenho esportivo e acarretar uma série de efeitos adversos, sendo assim proibidos pela Agência Mundial Antidopagem. A contaminação de suplementos pode ocorrer de maneira deliberada ou através de más práticas de produção, em que são encontrados traços dessas substâncias. Todavia, ambos os casos exigem atenção, já que uma contaminação de apenas 0,00005\% em massa pode levar ao doping. Neste sentido, estima-se que de $6,4 \%$ a $8,8 \%$ dos casos estejam relacionados ao consumo de suplementos contaminados. Perante estes fatos, os objetivos principais do trabalho foram: fazer uma revisão da literatura tanto em trabalhos nacionais quanto internacionais, no que concerne à contaminação de suplementos alimentares e sua relação com a dopagem não intencional, bem como orientar os consumidores a escolherem produtos mais seguros. Neste sentido, foi possível observar que os suplementos nacionais são, geralmente, mais seguros quanto à presença de substâncias proibidas, principalmente em relação à contaminação por agentes anabolizantes. Contudo, ainda é preciso um melhor controle de qualidade perante a contaminação/adulteração por estimulantes.

Palavras-chave: Suplementos alimentares; Contaminação; Doping; Esteroides anabolizantes; Pró-hormônios; estimulantes.

\section{Abstract}

The excessive consumption of food supplements, allied to unspecified legislation and inefficient quality control, can put in risk to the consumer's health because of the possible presence of contaminants, especially prohormones, anabolic steroids, and stimulants. These compounds can enhance sports performance and lead to a number of 
adverse effects, so they are prohibited by the World Anti-Doping Agency. Supplement contamination can occur deliberately or through poor manufacturing, in which traces of these substances are found. However, both cases require attention, as a contamination of only $0.00005 \%$ in mass can result in doping. Therefore, it is estimated that $6.4 \%$ to $8.8 \%$ of these cases are related to the consumption of contaminated supplements. Thus, the main objectives of this article were: to review the national and international literature regarding the contamination of food supplements and its relation to unintended doping, as well as to guide consumers to choose safer sources. In this sense, it was possible to observe that national supplements are generally safer in terms of the presence of prohibited substances, especially in relation to contamination of anabolic agents. On the other hand, there is still a need for better quality control regarding the contamination/adulteration of stimulants.

Keywords: Food supplements; Contamination; Doping; Anabolic steroids; Prohormones, stimulants.

\section{Introdução}

Suplementos alimentares são definidos como gêneros alimentícios que se destinam a complementar a dieta normal e que constituem fontes concentradas de substâncias com efeitos nutricionais e/ou fisiológicos. Essas substâncias podem incluir vitaminas, minerais, carboidratos, proteínas, aminoácidos, entre outros compostos, os quais são comercializados em diferentes formas, como comprimidos, líquidos, géis, pós ou barras. Contudo, apesar de grande parte destes produtos apresentarem-se de maneira similar a medicamentos, eles não possuem ação medicamentosa (Brasil, 2018; Van der Bijl \& Tutelyan, 2013).

Os números demonstram que os brasileiros estão aderindo cada vez mais ao consumo desse tipo de produto. Segundo dados da Associação Brasileira dos Fabricantes de Suplementos Nutricionais e Alimentos para Fins Especiais (Brasnutri), a indústria de suplementos faturou 1,46 bilhão de reais no ano de 2016, o que significou um aumento de $10 \%$ em relação ao período anterior (Associação Brasileira dos Fabricantes de Suplementos Nutricionais e Alimentos para Fins Especiais, 2016). Já em esfera global, o faturamento chegou, no mesmo ano, a 138,8 bilhões de dólares (Zion Market Research, 2017).

Normalmente, a utilização de suplementos alimentares é maior em atletas do que na população geral (Knapik et al., 2016), sendo praticamente "endêmica" quando se trata de esportistas de elite (Maughan, 2013). Há uma grande variabilidade nos dados sobre a prevalência do uso desses produtos por parte dos atletas, uma vez que os estudos são realizados em diversos países, englobando diferentes suplementos e modalidades esportivas (Knapik et al., 2016), porém todos os trabalhos mostram uma prevalência alta, entre 47\% e 100\% (Braun et al., 2009; Maughan et al., 2007; Nabuco et al., 2017). Apesar da divergência dos dados, os motivos para o uso de suplementos são basicamente os mesmos: aumento da energia e força muscular, melhora no desempenho esportivo, na manutenção da saúde geral e do sistema imunológico; prevenção de deficiências nutricionais, recuperação mais rápida de lesões e, por fim, compensar alimentação deficiente em alguns tipos de nutrientes (Elia et al., 2016; Kerksick et al., 2018). Os consumidores, ao adquirirem os suplementos, esperam que estes sejam adequados a esses propósitos (apesar de ser restrito o número de substâncias com real eficiência comprovada) (Mathews, 2018; Maughan et al., 2013) e, para que isso aconteça, é necessário que os produtos contenham todos os ingredientes citados no rótulo e que estes estejam em quantidades adequadas. Além disso, é fundamental que o suplemento não apresente nenhuma outra substância além do que esteja especificado, ou seja, nenhuma contaminação.

Todavia, há inúmeras evidências de que isso não é sempre o que acontece. Desde o final da década de 1990, estudos sobre a contaminação de suplementos nutricionais vêm sendo realizados (Kamber et al., 2001; Geyer et al., 2001). Os relatos presentes na literatura abrangem desde a presença de metais potencialmente tóxicos, como mercúrio (Finke et al., 2015) e chumbo (Poniedziałek et al., 2018), a microrganismos, como a Salmonella (Falkenstein, 2011) e, principalmente, substâncias com propriedades farmacológicas, com destaque para pró-hormônios, esteroides anabolizantes e estimulantes (Geyer et al., 2011). Todo tipo de alteração pode colocar em risco a saúde do consumidor, porém uma maior atenção tem sido voltada para os 
contaminantes do último grupo, uma vez que estes podem causar uma série de efeitos adversos e, além disso, no meio esportivo podem levar a um resultado analítico adverso em um exame de controle de dopagem, o que pode ser configurado como dopagem não intencional (Geyer et al., 2011; Martínez-Sanz et al., 2017). A presença desses contaminantes é causada principalmente devido ao controle de qualidade ineficiente, o qual pode ter origem tanto através da ausência de boas práticas de produção, quanto na utilização de matériaprima impura, e, também, na ação deliberada dos fabricantes, onde o suplemento é adulterado intencionalmente (Geyer et al., 2008; Maughan, 2013; Van Thuyne et al., 2006).

É preciso ressaltar ainda que esses problemas estão relacionados à regulamentação dos suplementos alimentares (Petroczi et al., 2011; Van der Bijl, 2014a; Justa Neves \& Caldas, 2015). Apesar de existirem leis que regulamentam tais produtos e suas rotulagens (as quais variam entre os países), ainda falta uma maior atenção quanto às avaliações sobre a eficácia e segurança destes. Os suplementos alimentares, em sua maioria, são enquadrados na categoria de alimentos, sendo assim, na grande parte dos casos, isentos da obrigatoriedade de registro nos órgãos reguladores. Consequentemente, não há necessidade da comprovação da segurança alimentar, bem como da validação científica do efeito físiológico e/ou nutricional atribuído ao produto pelo fabricante (Mathews, 2018; Van der Bijl, 2014a; Silva \& Ferreira, 2014). No Brasil, esse controle é feito pelo Ministério da Saúde, por meio da Agência Nacional de Vigilância Sanitária (ANVISA) (Brasil, 2018). A ANVISA tem por objetivo promover a proteção da saúde da população através do controle sanitário da produção e consumo de produtos e serviços submetidos à vigilância sanitária, inclusive dos ambientes, processos, insumos e das tecnologias a eles relacionados (Brasil, 2018).

Diante do que foi exposto, os objetivos deste estudo são: fazer uma revisão na literatura tanto nos trabalhos nacionais quanto internacionais, comparando-os, no que concerne à contaminação de suplementos alimentares por substâncias com propriedades farmacológicas, com enfoque nos pró-hormônios, agentes anabolizantes e estimulantes; discorrer sobre os efeitos adversos e o risco de doping não intencional em atletas; discutir a legislação brasileira e as recentes mudanças no âmbito regulatório, e, por fim, orientar como os consumidores podem escolher produtos mais seguros.

\section{Metodologia de pesquisa na literatura}

As informações presentes neste artigo foram obtidas através de sites e periódicos de organizações governamentais, bem como uma revisão bibliográfica foi realizada em artigos científicos indexados nas bases de dados ScienceDirect, PubMed e Portal de Periódicos CAPES, através dos termos "suplementos alimentares", "contaminação", "substâncias proibidas", "doping" e "doping não intencional”. É preciso destacar que a procura também foi realizada utilizando combinações entre as palavras avaliadas, por exemplo "contaminação de suplementos alimentares", com o objetivo de direcionar melhor os artigos encontrados. Além disso, também foram pesquisados os respectivos termos em inglês "nutritional supplements", "contamination", "prohibited substances" e "non-intentional doping". Por fim, referências pertinentes presentes nos artigos avaliados também foram utilizadas para a construção do manuscrito final. A seleção dos trabalhos abordados foi realizada de maneira independente por um só pesquisador, e foram incluídos apenas estudos realizados entre 2000 e setembro de 2019.

Ao todo, 41 artigos foram selecionados para a leitura do resumo, 26 foram escolhidos para avaliação de todo texto e, posteriormente, 14 foram inclusos neste artigo de revisão. Neste sentido, foram incluídos trabalhos que relatavam suplementos alimentares contaminados ou adulterados com substâncias proibidas pela Agência Mundial Antidopagem (AMA). Sendo assim, artigos que reportavam outros tipos de contaminações ou adulterações foram excluídos. 


\section{Regulamentação dos suplementos alimentares}

Apenas em julho de 2018 foi estabelecido um marco regulatório específico para suplementos alimentares no Brasil (RDC 243/2018) (Brasil, 2018). Anteriormente, o que era considerado "suplemento" podia ser enquadrado em diferentes normas de alimentos regulados pela ANVISA, como: Suplementos Vitamínicos e Minerais (Portaria 32/1998); Alimentos para Gestantes ou Nutrizes (Portaria 223/1998); Novos Produtos e Novos Ingredientes (RDC 16/1999); Alimentos com Alegações de Propriedade Funcional e/ou de Saúde (RDC 19/1999); Substâncias Bioativas e Probióticos (RDC 02/2002) e Alimentos para Atletas (RDC 18/2010) (Brasil, 2019). Este antigo arcabouço normativo era fragmentado, com lacunas regulatórias, além de apresentar sobreposições entre as categorias e requisitos desatualizados, fatos estes que poderiam ser prejudiciais tanto para os fabricantes quanto para consumidores (Silva \& Ferreira, 2014). Desta maneira, com o objetivo de fornecer um delineamento regulatório mais organizado e seguro quanto à comercialização e utilização destes produtos, foi implementado o marco regulatório no ano de 2018, estabelecendo-se assim a categoria "suplementos alimentares" na legislação brasileira, a qual reuniu todas as classes de alimentos citadas anteriormente, incluindo também uma de medicamentos (Medicamentos Específicos Isentos de Prescrição) (Brasil, 2019).

Além da criação de uma categoria específica para suplementos alimentares, o novo marco normativo também instituiu novas definições, regras de composição, qualidade e rotulagem, incluindo até uma atualização da lista de constituintes permitidos e seus limites de uso (Brasil, 2019). Todos esses pontos citados são positivos com relação à segurança e eficácia dos itens em questão. Contudo, um aspecto foi mantido em relação à legislação anterior: apenas os produtos contendo enzimas ou probióticos necessitam de registro sanitário na ANVISA. Consequentemente, uma gama muito grande de suplementos não possui a obrigatoriedade da comprovação de segurança alimentar e da validação científica do efeito atribuído ao produto (Brasil, 2002, 2019). Sendo assim, ainda há uma lacuna que pode facilitar a contaminação e/ou adulteração de suplementos alimentares.

Todos os suplementos lançados após o marco regulatório terão que ser adequados à nova legislação, enquanto os já presentes no mercado terão cinco anos (um período, talvez, demasiadamente longo) para a adequação às novas regras (Brasil, 2019). Apesar deste grande período de "adaptação" e da lacuna acima citada, espera-se que o novo marco normativo corrija uma série de irregularidades que ocorriam anteriormente, como o exemplificado a seguir.

A fragilidade da antiga regulamentação brasileira é bem ilustrada no trabalho realizado por Silva \& Ferreira (2014), em que uma série de não conformidades foi encontrada na verificação da situação legal de produtos vendidos como suplementos alimentares na internet. Nessa pesquisa foram identificados 3526 suplementos comercializados em 36 websites. Constatou-se que $55,5 \%$ de todos os sites pesquisados $(\mathrm{n}=22)$ ofertavam suplementos contendo compostos não reconhecidos pela ANVISA. Ainda, $27 \%(\mathrm{n}=10)$ dos sítios de vendas comercializavam produtos de origem animal como se fossem "fitoterápicos", como exemplo: gelatina e colágeno; óleo de peixe, óleo de tubarão e fígado dessecado. Além disso, $80 \%$ dos produtos pesquisados foram registrados nas categorias Alimentos para Atletas; Novos Produtos e Novos Ingredientes; ou Suplementos Vitamínicos e Minerais, categorias isentas de registro sanitário. Outro dado alarmante exposto no trabalho mostra que cerca de $63 \%$ dos itens $(n=2223)$ eram comercializados utilizando termos proibidos pela ANVISA, como "promoção do emagrecimento", "hipertrofia", "cura", "anabolismo" e "queima de gordura" (Brasil, 2013). Por fim, foi observado também que 43,3\% ( $\mathrm{n}=26)$ dos produtos destinados a "emagrecimento" e $35 \%(\mathrm{n}=14)$ dos produtos para "hipertrofia" estavam com registro irregular.

Contudo, não é somente o Brasil que apresenta problemas regulatórios relacionados a este assunto. Os Estados Unidos são um dos maiores produtores e consumidores de suplementos alimentares (Bailey et al., 2013). No país norte-americano, esses produtos são regulados na categoria de "alimentos" pelo FDA (Food and Drug Administration). Desta maneira, os suplementos alimentares são dispensados de registro, sendo os próprios fabricantes os responsáveis por garantir a segurança e rotulagem correta dos mesmos (Bailey et al., 
2013; Starr, 2015). Como discutido anteriormente, caso semelhante ocorre aqui no Brasil. O alarmante é que na literatura há diversos estudos que relacionam justamente essa ausência de necessidade de registro, aliada à baixa eficiência do controle de qualidade, com a presença de contaminantes em suplementos comercializados nos Estados Unidos e em diversos outros países (Geyer et al., 2008; Maughan, 2013; Van der Bijl \& Tutelyan, 2013). Portanto, é preciso ter uma cautela ainda maior com os suplementos importados, uma vez que apenas o fato de eles terem origem fora do país não garante que sejam seguros e, além disso, muitos dos produtos considerados como "suplementos" no exterior contêm (de maneira declarada ou não) estimulantes, hormônios, entre outras substâncias, as quais são proibidas de serem comercializadas no Brasil e, com relação ao âmbito esportivo, são consideradas como doping (Justa Neves \& Caldas, 2015).

\section{Contaminação de suplementos alimentares e doping não intencional}

Como bem destacado por Lentillon-Kaestner \& Ohl (2011), existem diferentes definições para "doping" na literatura, cada qual com diferentes limitações, o que pode confundir atletas e treinadores. Para o propósito deste artigo, será utilizada a definição presente no código mundial antidopagem de 2015, elaborado pela Agência Mundial Antidopagem (AMA). Segundo a AMA, doping (ou, o termo em português, dopagem) corresponde à violação das normas estabelecidas nos artigos 2.1 a 2.10 do código acima citado. Essas normas discorrem principalmente sobre a presença de uma substância proibida e/ou seu metabólito/marcador em uma amostra biológica do atleta; a utilização ou tentativa de utilização de uma substância ou método proibido; a recusa em fornecer material para análise; entre outros (Agência Mundial Antidopagem, 2015). A Tabela 1 apresenta os métodos e/ou as classes de substâncias proibidas pela Agência Mundial Antidopagem (2019). Com relação a esta definição e às discussões levantadas nesta revisão, é preciso ressaltar também o inciso 2.1.1, que deixa explícito que é um dever pessoal de cada atleta assegurar que nenhuma substância não autorizada esteja presente no seu organismo, bem como estes são responsáveis por qualquer substância, metabólito ou marcador presentes nas suas respectivas amostras, independente da intenção ou negligência. Consequentemente, $\mathrm{o}$ atleta poderá sofrer sanções mesmo que faça uso inocente de substâncias ou métodos proibidos (Agência Mundial Antidopagem, 2015; Parra et al., 2011). Neste sentido, uma das maiores causas de doping não intencional é o consumo de suplementos alimentares de forma abusiva e sem informação (Goel et al., 2004; Hughes, 2015).

Tabela 1. Lista de substâncias proibidas pela AMA (janeiro 2019) (Agência Mundial Antidopagem, 2019).

\begin{tabular}{lcc}
\hline Classe & Método/substância & Quando proibido \\
\hline S0 & Substâncias não aprovadas & Sempre \\
\hline S1 & Agentes anabolizantes & Sempre \\
\hline S2 & Hormônios peptídicos, fatores de crescimento, substâncias relacionadas e miméticos & Sempre \\
\hline S3 & Beta 2 agonistas & Sempre \\
\hline S4 & Moduladores hormonais e metabólicos & Sempre \\
\hline S5 & Diuréticos e agentes mascarantes & Sempre \\
\hline S6 & Estimulantes & Em competição \\
\hline S7 & Narcóticos & Em competição \\
\hline S8 & Canabinoides & Em competição \\
\hline S9 & Glicocorticoides & Em competição \\
\hline M1 & Sempre \\
\hline M2 & Manipulação do sangue e seus componentes & Sempre \\
\hline M3 & Manipulação química e física & Sempre \\
\hline P1 & Doping genético & Esportes em particular \\
\hline
\end{tabular}


Estudos relacionados ao uso desses produtos por parte dos atletas podem apresentar dados variados, uma vez que os números são muito dependentes do tipo de esporte, do nível de competição, bem como da idade e sexo dos desportistas. Um dos trabalhos mais importantes nessa área foi realizado por Tscholl e colaboradores (Tscholl et al., 2010), em que os dados de 3887 questionários foram coletados entre os anos de 2003 e 2008, referentes a 12 competições mundiais de atletismo (incluindo categorias júnior, sub 18, sub 20 e profissional). Essa pesquisa mostrou um consumo de 6523 suplementos (média de 1,7 por atleta), sendo a maior prevalência por parte de adultos. Uma taxa semelhante foi obtida em dados referentes às copas do mundo de futebol de 2002 e 2006 em pesquisa realizada pelo mesmo autor (Tscholl et al., 2008). Em estudo conduzido por Braun e colaboradores com atletas alemães jovens de alto nível, foi reportado que $80 \%$ utilizavam suplementos alimentares. A prevalência chega impressionantemente a 100\%, levando-se em consideração apenas atletas considerados "de ponta" (indivíduos que alcançaram boas colocações em nível olímpico e/ou mundial) (Braun et al., 2009). Já no Brasil, Nabuco e colaboradores identificaram uma prevalência de 47,3\% entre os esportistas entrevistados (Nabuco et al., 2017). Todavia, apesar dos altos níveis de consumo de suplementos, o conhecimento dos atletas perante esse assunto mostra-se limitado.

De maneira geral, as fontes de informação dos atletas com relação aos suplementos alimentares são de baixa qualidade, com a maioria das referências vindas dos treinadores, companheiros, amigos ou familiares (Froiland et al., 2004; Tian et al., 2009). Em estudo efetuado com atletas universitários, $86 \%$ não sabiam que suplementos poderiam apresentar efeitos adversos (Tian et al., 2009). Além disso, em um trabalho realizado com atletas australianos demonstrou-se que $62 \%$ dos desportistas entrevistados não conheciam o(s) ingrediente(s) ativo(s) do(s) suplemento(s) que consumiam, 57\% não sabiam dos possíveis efeitos adversos, $54 \%$ não tinham conhecimento sobre o mecanismo de ação, e $52 \%$ não sabiam a dose recomendada (Baylis et al., 2001). Já em pesquisa realizada em 2012 com 400 atletas norte-americanos, apenas 9\% apresentaram conhecimento adequado sobre nutrição esportiva (Torres-McGehee et al., 2012). Por fim, em estudo com atletas alemães, apenas 36\% sabiam que suplementos alimentares poderiam apresentar algum tipo de contaminante (Braun et al., 2009). Neste sentido, apesar de ser difícil uma exata quantificação da extensão do problema, é estimado que $6,4 \%$ a $8,8 \%$ dos resultados analíticos adversos em análises de controle de dopagem sejam causados por suplementos contaminados (Maughan, 2005; Outram \& Stewart, 2015). Esses casos são tão frequentes que o código mundial antidopagem (citado anteriormente) possui um inciso (10.5.1.1) que discorre justamente sobre a contaminação de suplementos alimentares. No inciso em questão está presente que, nas situações em que o atleta possa provar inexistência de culpa ou negligência significativa, e que a substância proibida detectada teve origem em um produto contaminado, a pena poderá ser de, no mínimo, uma advertência (sem período de suspensão) e, no máximo, dois anos de suspensão, consoante grau de culpa do indivíduo (Agência Mundial Antidopagem, 2015).

Dentre os diferentes tipos de contaminantes que podem levar o atleta a apresentar um resultado analítico adverso em um exame antidopagem, as pesquisas mais recentes têm dado maior destaque aos pró-hormônios, esteroides anabolizantes e estimulantes, classes que serão discutidas em maior detalhe neste trabalho.

\subsection{Suplementos alimentares contaminados com pró-hormônios}

Desde 1996, suplementos alimentares contendo pró-hormônios estão disponíveis no mercado de nutrição esportiva (Geyer et al, 2008). Pró-hormônios são precursores androgênicos que são ativados in vivo, de forma enzimática, a esteroides anabolizantes, como testosterona e derivados (King et al., 2012). Essas substâncias são adquiridas, em muitos casos, devido às propagandas enganosas: estes compostos são tratados como "naturais" e ainda destacam que auxiliam no aumento dos níveis de testosterona, promovendo maior força e crescimento da massa muscular, porém com menores efeitos adversos do que a administração de esteroides androgênicos sintéticos. Contudo, estudos indicam que esses efeitos ergogênicos não ocorrem, de fato, em grande extensão, e os riscos para a saúde ainda são consideráveis (Hahner \& Allolio, 2010). Além disso, os pró-hormônios estão presentes na lista de substâncias proibidas pela Agência Mundial Antidopagem (Classe S1) (Agência Mundial Antidopagem, 2019) e possuem a comercialização proibida em vários países (Van der Bijl, 2014b).

Muitos trabalhos apontam que diversos suplementos pró-hormonais contêm outras substâncias além das declaradas, bem como apresentam concentrações diferentes do que está descrito no rótulo (Ayotte et al., 2001; Baume et al., 2006; Green et al., 2001). Além disso, de maneira mais alarmante, há pesquisas que indicam que outros tipos de suplementos alimentares, como os de origem proteica, vitaminas, minerais, creatina, entre outros, podem estar contaminados com o grupo de substâncias em questão (Geyer et al., 2008; Kamber et al., 2001). 
Um dos estudos mais relevantes sobre o assunto foi realizado por Geyer e colaboradores, entre 2001 e 2002, no laboratório de Colônia (Alemanha) em parceria com o Comitê Olímpico Internacional (Geyer et al., 2004). Neste trabalho foram investigados 634 suplementos não hormonais, obtidos em 13 países diferentes, em busca de verificar a contaminação através da presença de testosterona, nandrolona, boldenona e seus respectivos pró-hormônios. Os resultados mostraram que 14,8\% $(n=94)$ dos suplementos continham ao menos uma dessas substâncias. Dentre todas as amostras consideradas positivas, $24,5 \%$ continham próhormônios da nandrolona e testosterona; $68,1 \%$ apenas pró-hormônios da testosterona e 7,5\% apenas próhormônios da nandrolona. Nenhuma amostra apresentou pró-hormônios da boldenona. O composto mais encontrado como contaminante foi o DHEA (desidroepiandrosterona), um pró-hormônio da testosterona que esteve presente em $63,2 \%$ das amostras positivas. A maioria dos suplementos contaminados teve origem na Holanda, com 8 amostras positivas em 31 analisadas (25,8\%), seguida pela Áustria, com 5 em 22 (22,7\%), Reino Unido, com 7 em 37 (18,9\%), e Estados Unidos, com 45 suplementos contaminados em 245 investigados $(18,8 \%)$. Os pesquisadores consideraram que a maioria das contaminações ocorreu de maneira acidental, uma vez que grande parte das concentrações dos pró-hormônios nas amostras positivas eram baixas e variadas (entre 0,01 a $5 \mu \mathrm{g} \mathrm{g}^{-1}$ ). Este aspecto é reforçado pelo fato de que a incidência de contaminação em empresas que, além dos referidos suplementos, também fabricavam pró-hormônios, foi três vezes maior do que as não produtoras. Desta maneira, a contaminação ocorreria de maneira cruzada, através de más práticas de produção e transporte dos produtos.

Concentrações muito baixas dos contaminantes podem não causar efeitos adversos, porém podem levar a um resultado analítico adverso em um exame antidopagem. Em estudo realizado no Reino Unido (Watson et al., 2008), 20 voluntários ingeriram $500 \mathrm{~mL}$ de água juntamente com $5 \mathrm{~g}$ de um suplemento de creatina contaminado com diferentes quantidades $(1,0 ; 2,5$ e 5,0 $\mu \mathrm{g})$ de 19-norandrostenodiona, um próhormônio da nandrolona. Amostras de urina dos voluntários foram analisadas e foi observado que era possível detectar a 19-norandrosterona (um dos metabólitos da nandrolona) em concentrações consideradas como doping em 25\% dos indivíduos que ingeriram o suplemento contaminado com 2,5 $\mu \mathrm{g}$ do pró-hormônio. Já a ingestão de creatina contendo $5,0 \mu \mathrm{g}$ do contaminante fez com que $75 \%$ das pessoas avaliadas apresentassem níveis do determinado metabólito mais altos que o permitido pela AMA. Ou seja, uma contaminação de apenas $0,00005 \%$ em massa pode resultar em graves problemas ao atleta.

\subsection{Suplementos alimentares contaminados com esteroides anabolizantes androgênicos}

Esteroides anabolizantes androgênicos (EAAs) correspondem a um grupo de substâncias sintéticas que são quimicamente similares e mimetizam a ação da testosterona endógena (Schänzer, 1996). Os esteroides mais comuns, também chamados de clássicos, incluem a metandienona, o estanozolol, a boldenona, a oxandrolona, e outros. Apesar de os EAAs serem administrados para o tratamento/controle de algumas doenças, como o hipogonadismo e osteoporose, tais substâncias vêm sendo muito utilizadas de forma não terapêutica e indiscriminada, com objetivos de melhorar o desempenho esportivo e também auxiliar na parte estética (Abrahin et al., 2013). No âmbito esportivo, os EAAs (assim como os pró-hormônios) enquadramse na Classe S1 (agentes anabolizantes) de substâncias proibidas pela Agência Mundial Antidopagem (2019), categoria que representa, normalmente, a maioria dos casos de doping. No ano de 2012 foram reportados 4500 resultados analíticos adversos pela Agência Mundial Antidopagem, sendo os agentes anabolizantes responsáveis por 50\% dos casos (Geyer et al., 2014). Já nos Jogos Olímpicos e Paralímpicos realizados no Rio de Janeiro em 2016, essa prevalência foi menor, representando 17\% dos casos (Pereira et al., 2017).

O uso abusivo das substâncias pertencentes a esta classe pode levar a uma série de efeitos adversos, como alterações nos níveis de colesterol, acne, diminuição da fertilidade e libido, problemas cardiovasculares, aumento da agressividade, câncer hepático, entre outros (Ambrose, 2004). Sendo assim, a comercialização desses compostos na forma de "suplementos alimentares" é proibida em diversos países, incluindo o Brasil (Brasil, 1998). Contudo, muitos desses produtos estão livremente disponíveis em diversos sites nacionais e internacionais (Petroczi et al., 2011; Silva \& Ferreira, 2014).

Desde 2002 têm sido detectados suplementos que apresentam grandes quantidades (maiores que $1 \mathrm{mg} \mathrm{g}^{-1}$ ) de esteroides "clássicos" não declarados nos rótulos, ou declarados com um nome fíctício, o que caracteriza uma adulteração (Geyer et al., 2011). Outros casos referentes à contaminação com esteroides indicam que a 
matéria-prima utilizada para fabricação dos suplementos pode ser a origem do problema. Muitos materiais são importados de empresas farmacêuticas chinesas, onde não há uma fiscalização adequada, podendo gerar uma série de contaminações cruzadas com o uso da mesma linha de produção, ou do transporte inadequado dos produtos (Geyer et al., 2004). Caso similar ocorreu na Alemanha, no final de 2005, onde uma empresa fabricante de suplementos teve muitos dos seus itens confiscados. As análises de tabletes de magnésio e multivitamínicos detectaram a presença de traços de metandienona e estanozolol (concentrações entre 5 e $50 \mathrm{ng} \mathrm{g}^{-1}$ ) nestes produtos. Nessa fábrica, tanto os suplementos vitamínicos quanto os anabolizantes eram produzidos na mesma linha de montagem, praticamente no mesmo intervalo de tempo, gerando assim a contaminação (Geyer et al., 2006). Outros relatos da contaminação/adulteração de suplementos alimentares por esteroides anabolizantes podem ser encontrados em mais trabalhos realizados em laboratórios estrangeiros (Baume et al., 2006; Judkins et al., 2007; Martello et al., 2007; Stepan et al., 2008).

Além dos problemas relacionados aos esteroides clássicos, atualmente também é preciso ter atenção aos denominados designer steroids, ou esteroides projetados. Esses compostos foram, de maneira geral, sintetizados nos anos 1960 e testados apenas em animais, com o objetivo de averiguar seus efeitos anabólicos e androgênicos. Essas substâncias não são produzidas por nenhuma empresa farmacêutica com o intuito de uso clínico, sendo sintetizadas exclusivamente pelo "mercado negro" de suplementos (Cavalcanti et al., 2013; Van der Bij1, 2014b). Na lista de substâncias proibidas pela AMA, o uso de designer steroids enquadrase na Classe S0, a qual abrange substâncias que não estão presentes em nenhuma outra categoria e que não têm aprovação de nenhuma autoridade regulamentar de saúde para uso terapêutico (Agência Mundial Antidopagem, 2019). O uso de "suplementos" contendo esteroides projetados fica ilustrado em um caso que ocorreu no início dos anos 2000, quando as análises de urina de diversos atletas apresentaram sinais desconhecidos e levantaram suspeitas em relação ao uso de substâncias dopantes. Um estudo mais detalhado levou à identificação dessas substâncias como sendo os metabólitos da androstatrienediona e da 6-oxoandrostenediona. Os resultados foram atribuídos ao "suplemento" Novedex Xtreme, que era anunciado como inibidor da aromatase e potencializador dos níveis de testosterona. Na realidade, este produto continha os esteroides projetados androstatrienediona e 6-oxo-androstenediona, mais conhecido como "6-OXO" (Van Thuyne et al., 2005).

Em relação aos estudos realizados no Brasil, a contaminação de suplementos por esteroides anabolizantes androgênicos ou pró-hormônios é algo mais difícil de acontecer, pois, ao contrário de outros países, esses agentes anabolizantes apresentam um preço muito elevado e também correspondem a drogas prescritas e não podem ser vendidos como suplementos. Isso faz com que diminua a chance de haver contaminações cruzadas durante a elaboração desses produtos (Costa et al., 2020). Contudo, é preciso haver um cuidado com suplementos importados e/ou adquiridos fora do país. Em estudo realizado por Cavalcanti e colaboradores, um "suplemento" hormonal obtido pela internet foi analisado e se constatou que ele continha, na realidade, metilestembolona, um exemplo de designer steroid que não apresenta nenhum tipo de regulamentação para uso (Cavalcanti et al., 2013). Além disso, em outro trabalho realizado em território nacional, Justa Neves e Caldas reportaram a análise de 2898 suplementos apreendidos pela Polícia Federal, sendo que 180 produtos apresentaram-se contaminados/adulterados com agentes anabolizantes ou estimulantes (Justa Neves \& Caldas, 2015). Destes suplementos, apenas 5\% foram adquiridos no Brasil.

\subsection{Suplementos alimentares contaminados com estimulantes}

Estimulantes são substâncias que agem diretamente no sistema nervoso central, aumentando (estimulando) suas atividades. Consequentemente, esses compostos são utilizados com o intuito de aumentar a concentração e o estado de alerta, bem como levar a uma diminuição da sensação de fadiga (Docherty, 2008; Thevis et al., 2010; Pereira \& Sardela, 2014). Por apresentarem o potencial risco de causar palpitações, agitação, insônia, tremores e alteração da regulação térmica, essas substâncias são proibidas pela Agência Mundial Antidopagem, enquadrando-se na Classe S6 (agentes estimulantes), sendo a cafeína o único composto desse grupo que possui uso permitido (porém monitorado) (Agência Mundial Antidopagem, 2019). Contudo, assim 
como no caso de agentes anabolizantes, a compra de produtos contendo estimulantes pode ser facilmente realizada pela internet (Viana et al., 2016).

Os primeiros relatos sobre suplementos contendo estimulantes não declarados nos rótulos foram publicados em 2002. No estudo em questão, foram analisados 69 suplementos de atletas alemães que participariam das Olimpíadas de Inverno de Salt Lake City, nos Estados Unidos. Ao todo 14 amostras estavam contaminadas com estimulantes, sendo que 12 continham cafeína, 3 continham efedrina, e em 1 estava presente a substância MDMA (metilenodioximetanfetamina), também conhecida como "ecstasy" (Schilt et al., 2002; De Hon \& Coumans, 2007). Em outro estudo similar, 110 suplementos foram analisados, sendo que 14 apresentaram cafeína e 2 continham efedrina e análogos (pseudoefedrina e metilefedrina) (Parr et al., 2003). Em relação ao doping não intencional, os estimulantes que levantam maior preocupação são justamente as do grupo das efedrinas, juntamente com a metilhexanamina e a sibutramina.

No caso de suplementos contendo efedrinas, a maior atenção recai sobre os produtos derivados da Ma Huang, uma planta de origem chinesa que contém naturalmente estes estimulantes. Em muitas situações, no rótulo consta apenas o nome da planta, sem mencionar os ingredientes ativos. Caso semelhante ocorre com suplementos de Citrus aurantium (Geyer et al., 2011; Van der Bij1, 2014a). Já os problemas em relação à presença de metilexanamina também são oriundos da má rotulagem dos produtos. O doping inadvertido pode surgir devido ao fato de esta substância poder constar no rótulo sob diversos outros nomes (sendo eles químicos ou comerciais). Por exemplo: 1,3-dimetilamina; metilexanamina; Forthane ${ }^{\circledR}$; óleo de gerânio; entre outros (Van der Bijl, 2014a). Apesar dos diversos avisos com cuidados em relação a produtos tidos como "naturais", muitos atletas continuam falhando em exames de controle de dopagem por causa dessas substâncias (Martínez-Sanz et al., 2017).

Já em relação à sibutramina, este estimulante pode estar presente em doses terapêuticas e supraterapêuticas em cápsulas, pós e chás de “emagrecimento" (Jung et al., 2006; Koehler et al., 2007; Vidal \& Quandte, 2006). A sibutramina é um anorexígeno sintético que em 2016 teve liberada a fabricação e comercialização no Brasil com a retenção de prescrição médica (Brasil, 2015). Contudo, o uso terapêutico deste composto gera muita polêmica. A Agência Europeia de Medicina, por exemplo, recomendou a retirada desse produto no mercado devido aos grandes riscos associados ao seu consumo, os quais incluem, principalmente, aumento da pressão arterial e da frequência cardíaca (Galhardo et al., 2010). Além da sibutramina, os denominados "suplementos para emagrecer" podem estar contaminados com diversas outras substâncias, como diferentes tipos de estimulantes, supressores de apetite, antidepressivos, diuréticos e laxativos. Segundo dados do FDA, cerca de 39\% desses produtos apresentam algum tipo de contaminante (U.S. Food and Drug Administration, 2016).

Este fato fica bem ilustrado em pesquisas recentes realizadas em território nacional. Em estudo efetuado em colaboração com a Polícia Federal (Justa Neves \& Caldas, 2017), 213 suplementos (em sua maioria produtos para "perda de peso") foram analisados, detectando-se a presença de drogas não declaradas em 28 amostras. Dentre as substâncias encontradas, destacam-se a anfepramona, sibutramina e femproporex. Neste sentido, os dois últimos compostos também foram relatados em estudo realizado na Universidade Federal de Santa Maria (Carvalho et al., 2012). No trabalho em questão, 109 suplementos foram adquiridos em nove diferentes estados brasileiros, sendo que quatro amostras estavam contaminadas com sibutramina e/ou femproporex. Já em outra pesquisa da mesma universidade foram analisados 94 suplementos obtidos de 30 diferentes websites brasileiros, detectando-se sinefrina em três amostras e efedrina em uma (Viana et al., 2016).

Por fim, outras duas pesquisas realizadas no Brasil também chamam a atenção quanto à contaminação por estimulantes. Em trabalho realizado pelo Instituto Nacional de Metrologia, Qualidade e Tecnologia (Inmetro), foram analisadas 15 marcas diferentes de suplementos proteicos derivados do soro do leite (whey protein), e apenas uma apresentou conformidade para todos os itens avaliados (quantidade, teor e origem proteica; teor de carboidratos, presença substâncias não declaradas e rotulagem) (Garrido et al., 2016; Instituto Nacional de Metrologia, Qualidade e Tecnologia, 2014). Com relação às substâncias não declaradas, cinco produtos avaliados apresentaram cafeína em sua constituição. Ainda no que diz respeito à análise de whey protein, em estudo realizado no Laboratório Brasileiro de Controle de Dopagem (LBCD) foram verificadas adulterações em 7 das 11 marcas de suplementos proteicos derivados do soro do leite avaliados (Roiffé et al., 2019). Quatro desses produtos continham benfluorex, um estimulante que está associado à morte de cerca de 1300 pessoas na França no período de 1976 a 2009. Essa substância era comercializada na forma de medicamento utilizado para diminuir o apetite e também no tratamento da hiperlipidemia e diabetes tipo 2 (Fournier \& Zureik, 2012). 
Os estudos nacionais e internacionais relacionados à contaminação/adulteração de suplementos alimentares com pró-hormônios, esteroides anabolizantes ou estimulantes mencionados neste review estão presentes na Tabela 2 .

Tabela 2. Estudos relacionados à contaminação ou adulteração de suplementos alimentares por substâncias proibidas pela AMA (organizados por ordem alfabética).

\begin{tabular}{|c|c|c|c|c|}
\hline Autores (ano) & País & Objetivo & Amostra & Principais resultados \\
\hline $\begin{array}{l}\text { Baume et al. } \\
\qquad(2006)\end{array}$ & Suíça & $\begin{array}{l}\text { Análise de estimulantes e } \\
\text { esteroides anabolizantes em } \\
\text { suplementos alimentares }\end{array}$ & $\begin{array}{c}103 \text { diferentes } \\
\text { suplementos alimentares } \\
\text { comprados pela internet }\end{array}$ & $\begin{array}{l}3 \text { produtos continham altas } \\
\text { concentrações de metandienona }\end{array}$ \\
\hline $\begin{array}{l}\text { Carvalho et al. } \\
\text { (2012) }\end{array}$ & Brasil & $\begin{array}{l}\text { Análise de estimulantes em } \\
\text { suplementos alimentares }\end{array}$ & 109 suplementos & $\begin{array}{l}4 \text { amostras contaminadas com } \\
\text { sibutramina e/ou femproporex }\end{array}$ \\
\hline $\begin{array}{l}\text { Cavalcanti et al. } \\
\text { (2013) }\end{array}$ & Brasil & $\begin{array}{l}\text { Análise de suplemento pró- } \\
\text { hormonal importado }\end{array}$ & $\begin{array}{l}1 \text { suplemento pró- } \\
\text { hormonal }\end{array}$ & $\begin{array}{c}\text { Suplementos em questão continham } \\
\text { metilestembolona, um designer steroid }\end{array}$ \\
\hline Geyer et al. (2004) & Alemanha & $\begin{array}{c}\text { Análise da presença de agentes } \\
\text { anabolizantes em suplementos } \\
\text { não hormonais }\end{array}$ & 634 amostras & $\begin{array}{c}94 \text { amostram contaminadas com pró- } \\
\text { hormônios }\end{array}$ \\
\hline Geyer et al. (2006) & Alemanha & $\begin{array}{l}\text { Análise de suplementos } \\
\text { multivitamínicos e minerais }\end{array}$ & $\begin{array}{c}13 \text { tabletes de } \\
\text { multivitamínicos e } \\
\text { minerais de } 5 \text { marcas } \\
\text { diferentes }\end{array}$ & $\begin{array}{l}8 \text { tabletes apresentavam traços de } \\
\text { estanozolol ou metandienona }\end{array}$ \\
\hline $\begin{array}{l}\text { Judkins et al. } \\
\qquad(2007)\end{array}$ & EUA & $\begin{array}{l}\text { Análise de estimulantes e } \\
\text { esteroides anabolizantes em } \\
\text { suplementos alimentares }\end{array}$ & 58 suplementos & $\begin{array}{l}6 \text { suplementos contaminados com } \\
\text { esteroides anabolizantes }\end{array}$ \\
\hline $\begin{array}{l}\text { Justa Neves \& } \\
\text { Caldas (2015) }\end{array}$ & Brasil & $\begin{array}{l}\text { Avaliar o perfil dos } \\
\text { suplementos alimentares no } \\
\text { "mercado clandestino" } \\
\text { brasileiro }\end{array}$ & $\begin{array}{l}2898 \text { suplementos } \\
\text { apreendidos }\end{array}$ & $\begin{array}{c}180 \text { produtos adulterados, } 74 \text { contendo } \\
\text { esteroides anabolizantes ou } \\
\text { estimulantes. }\end{array}$ \\
\hline $\begin{array}{l}\text { Justa Neves \& } \\
\text { Caldas (2017) }\end{array}$ & Brasil & $\begin{array}{l}\text { Determinação de cafeína e } \\
\text { estimulantes proibidos em } \\
\text { suplementos }\end{array}$ & 213 suplementos & $\begin{array}{c}28 \text { suplementos contaminados com } \\
\text { estimulantes, incluindo principalmente a } \\
\text { presença de anfepramona, sibutramina e } \\
\text { femproporex }\end{array}$ \\
\hline $\begin{array}{l}\text { Martello et al. } \\
\qquad(2007)\end{array}$ & Itália & $\begin{array}{c}\text { Detecção de esteroides } \\
\text { anabolizantes e efedrina em } \\
\text { suplementos }\end{array}$ & 64 suplementos & $\begin{array}{l}17 \text { suplementos contaminados: } 12 \text { com } \\
\text { esteroides anabolizantes, } 5 \text { com } \\
\text { estimulantes. }\end{array}$ \\
\hline Parr et al. (2003) & Alemanha & $\begin{array}{c}\text { Análise de cafeína e efedrina } \\
\text { em suplementos }\end{array}$ & 110 suplementos & $\begin{array}{c}2 \text { suplementos contaminados com } \\
\text { efedrina e análogos }\end{array}$ \\
\hline Roiffé et al. (2019) & Brasil & $\begin{array}{l}\text { Análise de diuréticos e } \\
\text { estimulantes em whey protein }\end{array}$ & $\begin{array}{l}11 \text { marcas diferentes de } \\
\text { whey protein }\end{array}$ & $\begin{array}{l}7 \text { amostras adulteradas: uma com } \\
\text { conivaptan e politiazida; dois continham } \\
\text { politiazida e benfluorex; e os demais } \\
\text { apresentaram politiazida ou benfluorex. }\end{array}$ \\
\hline Schilt et al. (2002) & Alemanha & $\begin{array}{l}\text { Análise dos suplementos que } \\
\text { seriam consumidos por atletas } \\
\text { alemães nas Olimpíadas de } \\
\text { Inverno } 2002\end{array}$ & 69 suplementos & $\begin{array}{c}14 \text { estavam contaminados. } 3 \text { continham } \\
\text { efedrina, } 1 \text { continha MDMA }\end{array}$ \\
\hline $\begin{array}{l}\text { Stepan et al. } \\
\qquad(2008)\end{array}$ & $\begin{array}{l}\text { República } \\
\text { Tcheca }\end{array}$ & $\begin{array}{c}\text { Determinação de esteroides } \\
\text { anabolizantes em suplementos } \\
\text { proteicos }\end{array}$ & 48 suplementos & $\begin{array}{c}3 \text { amostras positivas para agentes } \\
\text { anabolizantes }\end{array}$ \\
\hline Viana et al. (2016) & Brasil & $\begin{array}{l}\text { Análise de contaminantes em } \\
\text { suplementos obtidos pela } \\
\text { internet no Brasil }\end{array}$ & 94 suplementos & $\begin{array}{l}3 \text { amostras continham sinefrina e } 1 \\
\text { continha efedrina }\end{array}$ \\
\hline
\end{tabular}

\section{Como evitar o consumo de suplementos contaminados}

O primeiro passo para evitar problemas em relação ao consumo de suplementos é fazer o uso racional deste. A ingestão deste tipo de produto sem uma necessidade específica, doença ou deficiência não é recomendado e, em diversas circunstâncias, corresponde um risco desnecessário se o indivíduo (tanto atleta quanto não atleta) seguir uma boa dieta balanceada (Maughan \& Shirreffs, 2012). 
Já o doping não intencional está predominantemente relacionado ao uso de suplementos que apresentam um grande apelo aos seus efeitos fisiológicos, como elevado ganho de massa muscular e perda de peso, porém não está restrito somente a esse tipo de produto (Geyer et al., 2011). É indicado principalmente para atletas à procura por suplementos que possuem um selo de qualidade que garanta que o produto foi testado para a presença de substâncias proibidas. No Brasil ainda não há este tipo de garantia de qualidade, porém no exterior existem empresas terceirizadas que são contratadas para verificar a presença de compostos que podem levar a um resultado analítico adverso em um exame de controle de dopagem. Após passar nos testes, o produto recebe um selo de certificação para uso no esporte (Mathews, 2018) (Figura 1). É preciso ressaltar que a utilização de suplementos certificados diminui muito as chances de ingerir acidentalmente algum tipo de substância dopante, porém o risco não pode ser totalmente eliminado (Cadwallader \& Murray, 2015).

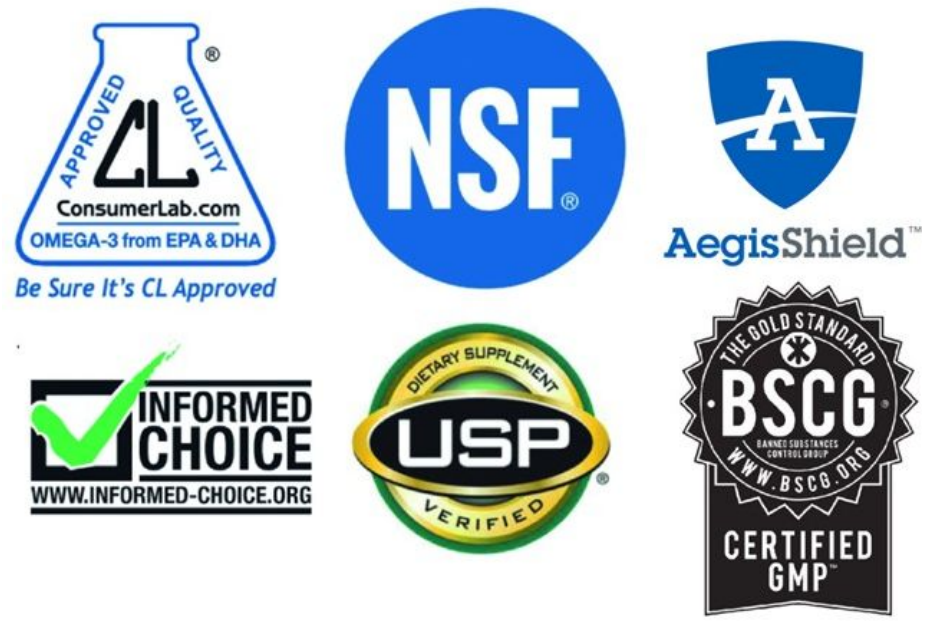

Figura 1. Exemplo de selos de garantia de qualidade para o uso de suplementos alimentares no esporte. Adaptado de Mathews (2018).

Por fim, existem bases de dados e que o atleta/consumidor pode fazer uma consulta para averiguar se determinado suplemento é considerado mais seguro para consumo. Como exemplo, há o site alemão Kölner Liste ( ${ }^{\circledR}$ (2019), o norte-americano NSF Certified Dietary Supplements (2019), e o holandês (Dopingautoriteit, 2019). No Brasil ainda não há um sistema similar.

\section{Conclusões}

A segurança de suplementos alimentares exige grande preocupação, visto que diversos estudos alertam sobre a presença de contaminantes, em especial pró-hormônios, esteroides anabolizantes e estimulantes. Além dos possíveis efeitos adversos, no âmbito esportivo o consumo desse tipo de produto ainda representa um risco de doping não intencional, uma vez que contaminações até mesmo em concentrações muito baixas podem levar o atleta a apresentar um resultado analítico adverso em um exame de controle de dopagem.

Espera-se que o novo marco regulatório possa fornecer um delineamento normativo mais organizado, seguro e eficaz quanto à fabricação e comercialização de suplementos alimentares, para que assim diversas irregularidades que eram encontradas no passado sejam corrigidas. Contudo, apesar da melhoria em diferentes aspectos, a nova legislação continua apresentando um ponto que precisa ser revisado, como o restrito número de suplementos que necessitam de registro sanitário na ANVISA, o que pode facilitar a presença de contaminantes em suplementos. Além disso, é preciso frisar que os problemas regulatórios não são exclusivos do Brasil. A compra de produtos importados também exige cuidados, com o agravante de que alguns compostos considerados como "suplementos" no exterior são proibidos de serem comercializadas no Brasil e estão presentes na lista de substâncias proibidas pela Agência Mundial Antidopagem. Neste sentido, 
esta revisão mostrou que os suplementos nacionais são, geralmente, mais seguros que os importados principalmente quanto à presença de agentes anabolizantes. Contudo, ainda é preciso maior controle de qualidade quanto à presença de estimulantes, visto que diversos estudos realizados no Brasil reportaram a contaminação/adulteração dos produtos com esses tipos de substâncias.

Por fim, o risco de ingestão acidental de substâncias perigosas/proibidas pode ser reduzido através da não utilização de suplementos alimentares que fazem um grande apelo aos seus efeitos fisiológicos. Ademais, é aconselhado o uso de produtos que apresentem certificações de segurança para o uso no esporte. É possível também consultar diferentes bancos de dados em sites estrangeiros, nos quais o consumidor pode verificar se o item a ser adquirido é considerado seguro. Infelizmente tal sistema ainda não existe no Brasil.

\section{Referências}

Abrahin, O. S. C., Souza, N. S. F., Sousa, E. C. D., Moreira, J. K. R., \& Nascimento, V. C. D. (2013). Prevalência do uso e conhecimento de esteroides anabolizantes androgênicos por estudantes e professores de educação física que atuam em academias de ginástica. Revista Brasileira de Medicina do Esporte, 19(1), 27-30. http://dx.doi.org/10.1590/S151786922013000100005

Agência Mundial Antidopagem - AMA. (2015). World anti-doping code. Recuperado em 16 de setembro de 2019, de https://www.wada-ama.org/sites/default/files/resources/files/wada-2015-worldantidop ing-code.pdf

Agência Mundial Antidopagem - AMA. (2019, janeiro). Prohibited list. Recuperado em 16 de setembro de 2019, de https://www.wada-ama.org/sites/default/files/wada_2019_english_prohibited_list.pdf

Ambrose, P. J. (2004). Drug use in sports: A veritable arena for pharmacists. Journal of the American Pharmacists Association, 44(4), 501-514. PMid:15372871. http://dx.doi.org/10.1331/1544345041475698

Associação Brasileira dos Fabricantes de Suplementos Nutricionais e Alimentos para Fins Especiais - Brasnutri. (2016).

Faturamento da Indústria de Suplementos Alimentares Cresce 10\%. Recuperado em 16 de setembro de 2019 , de http://www.brasnutri.org.br/ImagensRelease/edb980a7-8643-4794-a2392528fab9909 7.pdf

Ayotte, C., Lévesque, J. F., Cléroux, M., Lajeunesse, A., Goudreault, D., \& Fakirian, A. (2001). Sport nutritional supplements: Quality and doping controls. Canadian Journal of Applied Physiology, 26(Supl. 1), S120-S129. PMid:11897888. http://dx.doi.org/10.1139/h2001-047

Bailey, R. L., Gahche, J. J., Miller, P. E., Thomas, P. R., \& Dwyer, J. T. (2013). Why US adults use dietary supplements. JAMA Internal Medicine, 173(5), 355-361. http://dx.doi http://dx.doi.org/10.1001/jamainternmed.2013.2299

Baume, N., Mahler, N., Kamber, M., Mangin, P., \& Saugy, M. (2006). Research of stimulants and anabolic steroids in dietary supplements. Scandinavian Journal of Medicine \& Science in Sports, 16(1), 41-48. PMid:16430680. http://dx.doi.org/10.1111/j.1600-0838.2005.00442.x

Baylis, A., Cameron-Smith, D., \& Burke, L. M. (2001). Inadvertent doping through supplement use by athletes: Assessment and management of the risk in Australia. International Journal of Sport Nutrition and Exercise Metabolism, 11(3), $365-383$. PMid:11591885. http://dx.doi.org/10.1123/ijsnem.11.3.365

Brasil. Ministério da Saúde. Agência Nacional de Vigilância Sanitária - ANVISA. (1998, maio 12). Aprova o regulamento técnico sobre substâncias e medicamentos sujeitos a controle especial (Portaria n 334 , de $n^{\circ} 12$ de maio de 1998). Diário Oficial [da] República Federativa do Brasil, Brasília. Recuperado em 16 de setembro de 2019, de http://bvsms.saude.gov.br/bvs/saudelegis/svs/1998/prt0344_12_05_1998_rep.html

Brasil. Ministério da Saúde. Agência Nacional de Vigilância Sanitária - ANVISA. (2002, janeiro 7). Resolução RDC n² 2 , de 7 de janeiro de 2002. Diário Oficial [da] República Federativa do Brasil, Brasília. Recuperado em 16 de setembro de 2019 , de http://portal.anvisa.gov.br/documents/10181/2718376/\%281\%29RDC_02_2002_COMP.pdf/42355994-773f-4a7d-9b706887 acc1f0ad

Brasil. Ministério da Saúde. Agência Nacional de Vigilância Sanitária - ANVISA. (2013, março 30). Suplemento alimentar: Fique atento. Recuperado em 16 de setembro de 2019, de https://www.justica.gov.br/seusdireitos/consumidor/educacaoparaoconsumo/boletim -consumo-e-saude/anexos/consumo-e-saude-no30-suplementosalimentares-fique-atento-versao-final-22-04-2013.pdf

Brasil. Ministério da Saúde. Agência Nacional de Vigilância Sanitária - ANVISA. (2015, dezembro 16). Altera a Resolução da Diretoria Colegiada RDC n 50, de 25 de setembro de 2014, que dispõe sobre as medidas de controle decomercialização, prescrição e dispensaçãode medicamentos que contenham as substânciasanfepramona, femproporex, mazindole sibutramina, seus sais e isômeros,bem como intermediários e dá outras providências (Resolução RDC n 133, de 15 de dezembro de 2016). Diário Oficial [da] República Federativa do Brasil, Brasília. Recuperado em 16 de setembro de 2019, de http://portal.anvisa.gov.br/documents/10181/3136242/RDC_133_2016_.pdf/4f8401f3-b081-4b3e-ad38-bbf37d44f16f

Brasil. Ministério da Saúde. Agência Nacional de Vigilância Sanitária - ANVISA. (2018, julho 26). Dispõe sobre os requisitos sanitários dos suplementos alimentares. o (Resolução - RDC n 243, de 26 de julho de 2018). Diário Oficial [da] República Federativa do Brasil, Brasília. Recuperado em 16 de setembro de 2019, de http://www.in.gov.br/materia/lasset_publisher/Kujrw0TZC2Mb/content/id/34379969/do1-2018-07-27-resolucao-da-diretoria-colegiada-rdc-n-243-de-26-dejulho-de-2018-34379917 
Brasil. Ministério da Saúde. Agência Nacional de Vigilância Sanitária - ANVISA. (2019, fevereiro 4). Suplementos alimentares: Perguntas e respostas. Recuperado em 16 de setembro de 2019, de http://portal.anvisa.gov.br/documents/33916/2810640/Suplementos+Alimentares/a6fd2839-6d80-496a-becb-8b2122eff409

Braun, H., Koehler, K., Geyer, H., Kleinert, J., Mester, J., \& Schänzer, W. (2009). Dietary supplement use among elite young German athletes. International Journal of Sport Nutrition and Exercise Metabolism, 19(1), 97-109. PMid:19403956. http://dx.doi.org/10.1123/ijsnem.19.1.97

Cadwallader, A. B., \& Murray, B. (2015). Performance-enhancing drugs I: Understanding the basics of testing for banned substances. International Journal of Sport Nutrition and Exercise Metabolism, 25(4), 396-404. PMid:25675030. http://dx.doi.org/10.1123/ijsnem.2014-0185

Carvalho, L. D., Cohen, P. A., Silva, C. V., Moreira, A. P. L., Falcão, T. M., Dal Molin, T. R., \& Martini, M. (2012). A new approach to determining pharmacologic adulteration of herbal weight loss products. Food Additives \& Contaminants: Part A, 29(11), 1661-1667. PMid:22849359. http://dx.doi.org/10.1080/19440049.2012.706834

Cavalcanti, G., Leal, A., Garrido, B. C., Padilha, M. C., \& de Aquino Neto, F. R. (2013). Detection of designer steroid methylstenbolone in "nutritional supplement" using gas chromatography and tandem mass spectrometry: Elucidation of its urinary metabolites. Steroids, 78(2), 228-233. PMid:23200734. http://dx.doi.org/10.1016/j.steroids.2012.11.009

Costa, B. R. B., Padilha, M. C., Rodrigues, L. M. L., \& Roiffé, R. R. (2020). Analysis of anabolic agents in whey protein by gas chromatography coupled to triple quadrupole mass spectrometry. Food Analytical Methods, 13(11), 1-11. http://dx.doi.org/10.1007/s12161-020-01813-4

De Hon, O., \& Coumans, B. (2007). The continuing story of nutritional supplements and doping infractions. British Journal of Sports Medicine, 41(11), 800-805. PMid:17957017. http://dx.doi.org/10.1136/bjsm.2007.037226

Docherty, J. R. (2008). Pharmacology of stimulants prohibited by the World Anti-Doping Agency (WADA). British Journal of Pharmacology, 154(3), 606-622. PMid:18500382. http://dx.doi.org/10.1038/bjp.2008.124

Dopingautoriteit. (2019). Recuperado em 16 de setembro de 2019, de www.dopingautoriteit.nl/nzvt

Elia, M., Normand, C., Laviano, A., \& Norman, K. (2016). A systematic review of the cost and cost effectiveness of using standard oral nutritional supplements in community and care home settings. Clinical Nutrition, 35(1), 125-137. PMid:26309240. http://dx.doi.org/10.1016/j.clnu.2015.07.012

Falkenstein, D. (2011, março 31). Whey protein recalled due to Salmonella contamination. Food Poison Journal, Seattle. Recuperado em 16 de setembro de 2019, de http://www.foodpoisonjournal.com/foodborne-illness-outbreaks/whey-proteinrecalled-due-to-salmonella-contamination/

Finke, M. D., Rojo, S., Roos, N., van Huis, A., \& Yen, A. L. (2015). The European Food Safety Authority scientific opinion on a risk profile related to production and consumption of insects as food and feed. Journal of Insects as Food and Feed, 1(4), 245247. http://dx.doi.org/10.3920/JIFF2015.x006.

Fournier, A., \& Zureik, M. (2012). Estimate of deaths due to valvular insufficiency attributable to the use of benfluorex in France. Pharmacoepidemiology and Drug Safety, 21(4), 343-351. PMid:22318872. http://dx.doi.org/10.1002/pds.3213

Froiland, K., Koszewski, W., Hingst, J., \& Kopecky, L. (2004). Nutritional supplement use among college athletes and their sources of information. International Journal of Sport Nutrition and Exercise Metabolism, 14(1), 104-120. PMid:15129934. http://dx.doi.org/10.1123/ijsnem.14.1.104

Galhardo, J., Davis, N., Matthai, S., \& Shield, J. P. (2010). European Medicines Agency withdrawal for sibutramine. Archives of Disease in Childhood, 95(10), 856-856. PMid:20573736. http://dx.doi.org/10.1136/adc.2010.190959

Garrido, B. C., Souza, G. H. M. F., Lourenço, D. C., \& Fasciotti, M. (2016). Proteomics in quality control: Whey protein-based supplements. Journal of Proteomics, 147, 48-55. PMid:27072112. http://dx.doi.org/10.1016/j.jprot.2016.03.044

Geyer, H., Braun, H., Burke, L. M., Stear, S. J., \& Castell, L. M. (2011). A-Z of nutritional supplements: Dietary supplements, sports nutrition foods and ergogenic aids for health and performance. Part 22. British Journal of Sports Medicine, 45(9), 752754. PMid:21646366. http://dx.doi.org/10.1136/bjsports-2011-090180

Geyer, H., Mareck, U., Köhler, K., Parr, M. K., \& Schänzer, W. (2006). Cross contaminations of vitamin-and mineral-tablets with metandienone and stanozolol. In W. Schänzer, H. Geyer, A. Gotzmann \& U. Mareck (Eds.), Recent advances in doping analysis, 14 (pp. 11-16). Köln: Sport und Buch Strauß.

Geyer, H., Mareck-Engelke, U., Wagner, A., \& Schänzer, W. (2001). Analysis of "non-hormonal" nutritional supplements for prohormones. In Proceedings of the 19th Cologne Workshop on Dope Analysis. Cologne: Sport und Buch Strausse.

Geyer, H., Parr, M. K., Koehler, K., Mareck, U., Schänzer, W., \& Thevis, M. (2008). Nutritional supplements cross-contaminated and faked with doping substances. Journal of Mass Spectrometry, 43(7), 892-902. http://dx.doi.org/10.1002/jms.1452

Geyer, H., Parr, M. K., Mareck, U., Reinhart, U., Schrader, Y., \& Schänzer, W. (2004). Analysis of non-hormonal nutritional supplements for anabolic-androgenic steroids-results of an international study. International Journal of Sports Medicine, 25(2), 124-129. PMid:14986195. http://dx.doi.org/10.1055/s-2004-819955

Geyer, H., Schänzer, W., \& Thevis, M. (2014). Anabolic agents: Recent strategies for their detection and protection from inadvertent doping. British Journal of Sports Medicine, 48(10), 820-826. PMid:24632537. http://dx.doi.org/10.1136/bjsports2014-093526

Goel, D. P., Geiger, J. D., Shan, J. J., Kriellaars, D., \& Pierce, G. N. (2004). Doping-control urinalysis of a ginseng extract, ColdFX®, in athletes. International Journal of Sport Nutrition and Exercise Metabolism, 14(4), 473-480. PMid:15467104.

http://dx.doi.org/10.1123/ijsnem.14.4.473 
Green, G. A., Catlin, D. H., \& Starcevic, B. (2001). Analysis of over-the-counter dietary supplements. Clinical Journal of Sport Medicine, 11(4), 254-259. http://dx.doi.org/10.1097/00042752-200110000-00008

Hahner, S., \& Allolio, B. (2010). Dehydroepiandrosterone to enhance physical performance: Myth and reality. Endocrinology and Metabolism Clinics, 39(1), 127-139. PMid:20122454. http://dx.doi.org/10.1016/j.ecl.2009.10.008

Hughes, D. (2015). The world anti-doping code in sport: Update for 2015. Australian Prescriber, 38(5), 167-170.

PMid:26648655. http://dx.doi.org/10.18773/austprescr.2015.059

Instituto Nacional de Metrologia, Qualidade e Tecnologia - INMETRO. (2014). Programa de análise de produtos: Relatório final sobre a análise em suplementos proteicos para atletas: Whey protein. Brasília. Recuperado em 16 de setembro de 2019, de http://www.inmetro.gov.br/consumidor/produtos/Relatorio_Whey_Final.pdf

Judkins, C., Hall, D., \& Hoffman, K. (2007). Investigation into supplement contamination levels in the US market. Cambridgeshire, UK: HFL, Ltd. Recuperado em 16 de setembro de 2019, de http://www.mesomorphosis.com/blog/wpcontent/uploads/2008/11/hfl-supplement-research-report.pdf

Jung, J., Hermanns-Clausen, M., \& Weinmann, W. (2006). Anorectic sibutramine detected in a Chinese herbal drug for weight loss. Forensic Science International, 161(2-3), 221-222. PMid:16870382. http://dx.doi.org/10.1016/j.forsciint.2006.02.052

Justa Neves, D. B., \& Caldas, E. D. (2015). Dietary supplements: International legal framework and adulteration profiles, and characteristics of products on the Brazilian clandestine market. Regulatory Toxicology and Pharmacology, 73(1), 93-104. PMid:26107294. http://dx.doi.org/10.1016/j.yrtph.2015.06.013

Justa Neves, D. B., \& Caldas, E. D. (2017). Determination of caffeine and identification of undeclared substances in dietary supplements and caffeine dietary exposure assessment. Food and Chemical Toxicology, 105, 194-202. PMid:28366845. http://dx.doi.org/10.1016/j.fct.2017.03.063

Kamber, M., Baume, N., Saugy, M., \& Rivier, L. (2001). Nutritional supplements as a source for positive doping cases? International Journal of Sport Nutrition and Exercise Metabolism, 11(2), 258-263. PMid:11402257. http://dx.doi.org/10.1123/ijsnem.11.2.258

Kerksick, C. M., Wilborn, C. D., Roberts, M. D., Smith-Ryan, A., Kleiner, S. M., Jäger, R., Collins, R., Cooke, M., Davis, J. N., Galvan, E., Greenwood, M., Lowery, L. M., Wildman, R., Antonio, J., \& Kreider, R. B. (2018). ISSN exercise \& sports nutrition review update: Research \& recommendations. Journal of the International Society of Sports Nutrition, 15(1), 38. PMid:30068354. http://dx.doi.org/10.1186/s12970-018-0242-y

King, D. S., Baskerville, R., Hellsten, Y., Senchina, D. S., Burke, L. M., Stear, S. J., \& Castell, L. M. (2012). A-Z of nutritional supplements: Dietary supplements, sports nutrition foods and ergogenic aids for health and performance-Part 34 . British Journal of Sports Medicine, 46(9), 689-690. PMid:22711798. http://dx.doi.org/10.1136/bjsports-2012-091314

Knapik, J. J., Steelman, R. A., Hoedebecke, S. S., Austin, K. G., Farina, E. K., \& Lieberman, H. R. (2016). Prevalence of dietary supplement use by athletes: Systematic review and meta-analysis. Sports Medicine, 46(1), 103-123. PMid:26442916. http://dx.doi.org/10.1007/s40279-015-0387-7

Koehler, K., Geyer, H., Guddat, S., Orlovius, A., Parr, M. K., Thevis, M., \& Schänzer, W. (2007). Sibutramine found in chinese herbal slimming tea and capsules. In W. Schänzer, H. Geyer, A. Gotzmann \& U. Mareck (Eds.), Recent advances in doping analysis, 15 (pp. 367-370). Köln: Sport und Buch Strauß.

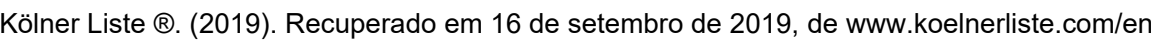

Lentillon-Kaestner, V., \& Ohl, F. (2011). Can we measure accurately the prevalence of doping? Scandinavian Journal of Medicine \& Science in Sports, 21(6), e132-e142. PMid:22126721. http://dx.doi.org/10.1111/j.1600-0838.2010.01199.x

Martello, S., Felli, M., \& Chiarotti, M. (2007). Survey of nutritional supplements for selected illegal anabolic steroids and ephedrine using LC-MS/MS and GC-MS methods, respectively. Food Additives and Contaminants, 24(3), 258-265. PMid:17364927. http://dx.doi.org/10.1080/02652030601013729

Martínez-Sanz, J., Sospedra, I., Ortiz, C., Baladía, E., Gil-Izquierdo, A., \& Ortiz-Moncada, R. (2017). Intended or unintended doping? A review of the presence of doping substances in dietary supplements used in sports. Nutrients, 9(10), 1093. PMid:28976928. http://dx.doi.org/10.3390/nu9101093

Mathews, N. M. (2018). Prohibited contaminants in dietary supplements. Sports Health, 10(1), 19-30. PMid:28850291. http://dx.doi.org/10.1177/1941738117727736

Maughan, R. J. (2005). Contamination of dietary supplements and positive drug tests in sport. Journal of Sports Sciences, 23(9), 883-889. PMid:16195040. http://dx.doi.org/10.1080/02640410400023258

Maughan, R. J. (2013). Quality assurance issues in the use of dietary supplements, with special reference to protein supplements. The Journal of Nutrition, 143(11), 1843S-1847S. http://dx.doi.org/10.3945/jn.113.176651

Maughan, R. J., \& Shirreffs, S. M. (2012). Nutrition for sports performance: Issues and opportunities. The Proceedings of the Nutrition Society, 71(1), 112-119. PMid:22000743. http://dx.doi.org/10.1017/S0029665111003211

Maughan, R. J., Depiesse, F., \& Geyer, H. (2007). The use of dietary supplements by athletes. Journal of Sports Sciences, 25(S1), S103-S113. http://dx.doi.org/10.1080/02640410701607395

Maughan, R. J., Greenhaff, P. L., \& Hespel, P. (2013). Dietary supplements for athletes: Emerging trends and recurring themes. Food, Nutrition and Sports Performance, 3, 65-74. http://dx.doi.org/10.4324/9781315873268-14

Nabuco, H. C. G., Rodrigues, V. B., Barros, W. M. D., Ravagnani, F. C. D. P., Espinosa, M. M., \& Ravagnani, C. D. F. C. (2017). Use of dietary supplements among Brazilian athletes. Revista de Nutrição, 30(2), 163-173. http://dx.doi.org/10.1590/167898652017000200002

NSF Certified Dietary Supplements. (2019). Recuperado em 21 de Março de 2021, de https://info.nsf.org/Certified/Dietary/. 
Outram, S., \& Stewart, B. (2015). Doping through supplement use: A review of the available empirical data. International Journal of Sport Nutrition and Exercise Metabolism, 25(1), 54-59. PMid:25722470. http://dx.doi.org/10.1123/ijsnem.2013-0174

Parr, M. K., Geyer, H., Sigmund, G., Köhler, K., \& Schänzer, W. (2003). Screening of nutritional supplements for stimulants and other drugs. In W. Schänzer, H. Geyer, A. Gotzmann \& U. Mareck (Eds.), Recent advances in doping analysis, 2. Köln: Sport und Buch Strauß.

Parra, R. M. T., Palma, A., \& Pierucci, A. P. T. R. (2011). Contaminação de suplementos dietéticos usados para prática esportiva. Revista Brasileira de Ciências do Esporte, 33(4), 1071-1084. http://dx.doi.org/10.1590/S0101-32892011000400018

Pereira, H. M. G., \& Sardela, V. F. (2014). Stimulant doping agents used in Brazil: Prevalence, detectability, analytical implications, and challenges. Substance Use \& Misuse, 49(9), 1098-1114. PMid:24766455.

http://dx.doi.org/10.3109/10826084.2014.907653

Pereira, H. M. G., Sardela, V. F., Padilha, M. C., Mirotti, L., Casilli, A., Oliveira, F. A., Albuquerque Cavalcanti, G., Rodrigues, L. M. L., Araujo, A. L. D., Levy, R. S., Teixeira, P. A. C., Oliveira, F. A. G., Duarte, A. C. G., Carneiro, A. C. D., Evaristo, J. A. M., Santos, G. R. C., Costa, G. C. V., Lima Castro, F., Nogueira, F. C. S., Scalco, F. B., Pizzatti, L., \& Aquino Neto, F. R. (2017). Doping control analysis at the Rio 2016 Olympic and Paralympic Games. Drug Testing and Analysis, 9(11-12), 1658-1672. PMid:29078043. http://dx.doi.org/10.1002/dta.2329

Petroczi, A., Taylor, G., \& Naughton, D. P. (2011). Mission impossible? Regulatory and enforcement issues to ensure safety of dietary supplements. Food and Chemical Toxicology, 49(2), 393-402. PMid:21087651.

http://dx.doi.org/10.1016/j.fct.2010.11.014

Poniedziałek, B., Niedzielski, P., Kozak, L., Rzymski, P., Wachelka, M., Rzymska, I., Karczewski, J., \& Rzymski, P. (2018). Monitoring of essential and toxic elements in multi-ingredient food supplements produced in European Union. Journal of Consumer Protection and Food Safety, 13(1), 41-48. http://dx.doi.org/10.1007/s00003-018-1148-y

Roiffé, R. R., Sardela, V. F., Lima, A. L. D. S., Oliveira, D. S., Aquino Neto, F. R. D., Lima, K. D. S. C., \& Cruz, M. N. D. S. D. (2019). Determination of adulterants in whey protein food supplements by liquid chromatography coupled to Orbitrap high resolution mass spectrometry. Brazilian Journal of Food Technology, 22, e2018206. http://dx.doi.org/10.1590/1981-6723.20618 Schänzer, W. (1996). Metabolism of anabolic androgenic steroids. Clinical Chemistry, 42(7), 1001-1020. http://dx.doi.org/10.1093/clinchem/42.7.1001

Schilt, R., van der Vlis, E., Vaes, W., Sterk, S. S., \& van Ginkel, L. A. (2002). Onderzoek naar het voorkomen van dopinggeduide stoffen in voedingsmiddelen in de aanloop naar de Olympische Winterspelen in Salt Lake City [Research into the prevention of doping in the nutrition of athletes preparing for the Winter Olympics in Salt Lake City]. Zeist, the Netherlands: TNO Nutrition and Food Research and the National Institute of Public Health and the Environment (RIVM).

Silva, L. F. M. D., \& Ferreira, K. S. (2014). Segurança alimentar de suplementos comercializados no Brasil. Revista Brasileira de Medicina do Esporte, 20(5), 374-378. http://dx.doi.org/10.1590/1517-86922014200501810

Starr, R. R. (2015). Too little, too late: Ineffective regulation of dietary supplements in the United States. American Journal of Public Health, 105(3), 478-485. PMid:25602879. http://dx.doi.org/10.2105/AJPH.2014.302348

Stepan, R., Cuhra, P., \& Barsova, S. (2008). Comprehensive two-dimensional gas chromatography with time-of-flight mass spectrometric detection for the determination of anabolic steroids and related compounds in nutritional supplements. Food Additives and Contaminants, 25(5), 557-565. PMid:18473210. http://dx.doi.org/10.1080/02652030701609228

Thevis, M., Sigmund, G., Geyer, H., \& Schänzer, W. (2010). Stimulants and doping in sport. Endocrinology and Metabolism Clinics, 39(1), 89-105, ix. PMid:20122452. http://dx.doi.org/10.1016/j.ecl.2009.10.011

Tian, H. H., Ong, W. S., \& Tan, C. L. (2009). Nutritional supplement use among university athletes in Singapore. Singapore Medical Journal, 50(2), 165-172. PMid:19296032.

Torres-McGehee, T. M., Pritchett, K. L., Zippel, D., Minton, D. M., Cellamare, A., \& Sibilia, M. (2012). Sports nutrition knowledge among collegiate athletes, coaches, athletic trainers, and strength and conditioning specialists. Journal of Athletic Training, 47(2), 205-211. PMid:22488287. http://dx.doi.org/10.4085/1062-6050-47.2.205

Tscholl, P., Alonso, J. M., Dollé, G., Junge, A., \& Dvorak, J. (2010). The use of drugs and nutritional supplements in top-level track and field athletes. The American Journal of Sports Medicine, 38(1), 133-140. PMid:19812387. http://dx.doi.org/10.1177/0363546509344071

Tscholl, P., Junge, A., \& Dvorak, J. (2008). The use of medication and nutritional supplements during FIFA World Cups 2002 and 2006. British Journal of Sports Medicine, 42(9), 725-730. PMid:18308873. http://dx.doi.org/10.1136/bjsm.2007.045187

U.S. Food and Drug Administration - FDA. (2016). Tainted products marketed as dietary supplements_CDER. Recuperado em 16 de setembro de 2019, de http://www.accessdata.fda. gov/scripts/sda/sdNavigation.cfm

Van der Bijl, P. (2014a). Dietary supplements containing prohibited substances: A review (Part 1). South African Journal of Sports Medicine, 26(2), 59-61. http://dx.doi.org/10.7196/sajsm.552

Van der Bijl, P. (2014b). Dietary supplements containing prohibited substances: A review (Part 2). South African Journal of Sports Medicine, 26(3), 87-90. http://dx.doi.org/10.7196/sajsm.553

Van der Bijl, P., \& Tutelyan, V. A. (2013). Dietary supplements containing prohibited substances. Voprosy Pitaniia, 82(6), 6-13. PMid:24741950.

Van Thuyne, W., Van Eenoo, P., \& Delbeke, F. T. (2006). Nutritional supplements: Prevalence of use and contamination with doping agents. Nutrition Research Reviews, 19(1), 147-158. PMid:19079882. http://dx.doi.org/10.1079/NRR2006122 
Van Thuyne, W., Van Eenoo, P., Mikulčíková, P., Deventer, K., \& Delbeke, F. T. (2005). Detection of androst-4-ene-3, 6, 17trione $(6-\mathrm{OXO} \otimes)$ and its metabolites in urine by gas chromatography-mass spectrometry in relation to doping analysis. Biomedical Chromatography, 19(9), 689-695. PMid:15828056. http://dx.doi.org/10.1002/bmc.496

Viana, C., Zemolin, G. M., Müller, L. S., Dal Molin, T. R., Seiffert, H., \& de Carvalho, L. M. (2016). Liquid chromatographic determination of caffeine and adrenergic stimulants in food supplements sold in Brazilian e-commerce for weight loss and physical fitness. Food Additives \& Contaminants: Part A, 33(1), 1-9. PMid:26560757.

Vidal, C., \& Quandte, S. (2006). Identification of a sibutramine-metabolite in patient urine after intake of a "pure herbal" Chinese slimming product. Therapeutic Drug Monitoring, 28(5), 690-692. PMid:17038887. http://dx.doi.org/10.1097/01.ftd.0000245392.33305.b0

Watson, P., Judkins, C., Houghton, E. D., Russell, C., \& Maughan, R. (2008). Supplement contamination: Detection of nandrolone metabolites in urine after administration of small doses of a nandrolone precursor. In Proceedings of the Nutrition Society, 67(OCE8). Cambridge: Cambridge University Press. http://dx.doi.org/10.1017/S0029665108000487.

Zion Market Research. (2017, janeiro 5). Dietary Supplements Market by Ingredients (Botanicals, Vitamins, Minerals, Amino Acids, Enzymes) for Additional Supplements, Medicinal Supplements and Sports Nutrition Applications - Global Industry Perspective, Comprehensive Analysis and Forecast, 2016-2022: Dietary supplements market globally will grow USD 220.3 billion by 2022 and increasing at 8.8\% CAGR through 2022. New York. Recuperado em 16 de setembro de 2019, de https://www.zionmarketresearch.com/report/dietary-supplements-market

Funding: None. 